\title{
Calix[6]quinone as high-performance cathode for lithium-ion battery
}

\author{
Weiwei Huang ${ }^{1,3 \dagger^{*}}$, Xueqian Zhang ${ }^{2 \dagger}$, Shibing Zheng ${ }^{1}$, Wenjun Zhou ${ }^{1}$, Jian Xie ${ }^{3}$, Zhinan Yang ${ }^{2^{*}}$ and \\ Qichun Zhang ${ }^{3 *}$
}

\begin{abstract}
Organic quinone compounds have attracted wide attention due to their high theoretical capacities. Here, a novel cyclic macromolecular calix[6]quinone (C6Q), which possesses 6 -quinone units and can provide 12 electrochemical active sites, has been applied as a promising cathode material in lithium ion batteries (LIBs). The as-fabricated LIBs exhibited an initial specific capacity as high as $423 \mathrm{~mA} \mathrm{~h} \mathrm{~g}^{-1}\left(C_{\text {theo }}=447 \mathrm{~mA} \mathrm{~h} \mathrm{~g}^{-1}\right)$ at $0.1 \mathrm{C}$. After 100 cycles, the capacity of $\mathrm{C} 6 \mathrm{Q}$ maintained at $216 \mathrm{~mA} \mathrm{~h} \mathrm{~g}^{-1}$, and even after 300 cycles, C6Q still achieved a high specific capacity of $195 \mathrm{~mA} \mathrm{~h} \mathrm{~g}^{-1}$ with negligible capacity fading (as compared with the $100^{\text {th }}$ cycle). Due to the large capacity and wide electrochemical window, C6Q can deliver a specific energy up to $1201 \mathrm{~W} \mathrm{~h} \mathrm{~kg}^{-1}$. In addition, the method of immobilizing C6Q with ordered mesoporous carbon (OMC) CMK-3 could further enhance the electrochemical performance of $\mathrm{C} 6 \mathrm{Q}$.
\end{abstract}

Keywords: calix[6]quinone, lithium-ion battery, organic, cathode, high-performance

\section{INTRODUCTION}

Till now, rechargeable lithium-ion batteries (LIBs) have been extensively used in the market, especially in many portable electronics [1-3]. However, conventional inorganic electrode materials face several serious issues, including huge energy consumption in preparation, high cost, and the contamination of the environment caused by excessive waste batteries [4-8]. Therefore, developing new low-cost high-performance electrode materials is considered as an important research direction for future innovative LIBs [9-14]. Specially, "organic batteries" have become a current hot topic because this type of batteries could be the next generation of environmentally friendly batteries. Compared with the traditional inorganic electrode materials, organic electrode materials have a lot of advantages, such as high theoretical specific capacity, strong designability of molecular structures, renewable constituent elements $(\mathrm{C}, \mathrm{H}, \mathrm{O}, \mathrm{N}$, etc.), good reversibility, high system security, low production cost and readily degradable property [15-23]. These merits could perfectly solve most of the flaws existing in inorganic electrode materials.

Among all organic electrode materials, quinone compounds are of the most outstanding candidates due to their excellent properties [24-27]. Quinone compounds, containing conjugated carbonyls, are widely found in nature. The two-electron redox reaction endows quinones with a higher theoretical capacity compared with other organic materials. Moreover, the reduction potentials of quinones are higher than those of other organic materials. For example, $p$-benzoquinone (BQ), the basic unit of the quinone structure, has a theoretical capacity up to $496 \mathrm{~mA} \mathrm{~h} \mathrm{~g}^{-1}$. Nevertheless, the high volatility and solubility [28] of quinone greatly limit its usage in LIBs. Up to now, anthraquinone (AQ) [28], dibenzothiophene (DBT) [28], calix[4]quinone (C4Q) [29-32], pillar[5]quinone (P5Q) $[33,34]$ and several other quinones derivatives have been widely reported. Huang et al. [29] first applied C4Q as cathode in LIBs and found that C4Q could deliver an initial capacity of $431 \mathrm{~mA} \mathrm{~h} \mathrm{~g}^{-1}$ ( $97 \%$ of $C_{\text {theo }}$ ) in the liquid electrolytes; however, the batteries only preserved a capacity approximating to $100 \mathrm{~mA} \mathrm{~h} \mathrm{~g}^{-1}$ after five cycles. Zheng et al. [30] applied C4Q as an electrode in sodiumion batteries (SIBs) and found that only $24 \mathrm{~mA} \mathrm{~h} \mathrm{~g}^{-1}$ of the capacity could be observed after 10 cycles. Zhu et al. [33] reported the use of P5Q in LIBs with only $50 \%$ ca-

\footnotetext{
${ }^{1}$ College of Environmental and Chemical Engineering, Yanshan University, Qinhuangdao 066004, China

${ }^{2}$ State Key Laboratory of Metastable Materials Science and Technology, Yanshan University, Qinhuangdao 066004, China

${ }^{3}$ School of Materials Science and Engineering, Nanyang Technological University, Singapore 639798, Singapore

${ }^{\dagger}$ Huang $\mathrm{W}$ and Zhang X contributed equally.

* Corresponding authors (emails: huangweiwei@ysu.edu.cn (Huang W); zhinanyang@ysu.edu.cn (Yang Z); qczhang@ntu.edu.sg (Zhang Q))
} 
pacity delivered after three cycles. Although all these organic electrode materials possess high theoretical capacities, their cycling performance is very poor. There are two reasons for these problems: (1) these materials are soluble in organic electrolytes, hence their capacities would continuously degrade during the cycling process $[27,35]$; and (2) the large interfacial resistances of quinone cathodes would result in low conductivity, resulting in poor rate performance $[4,29,36]$. Therefore, it is highly desirable to enhance the performance of quinone-based electrodes through some modification.

To address the solubility issue, quinone compounds can be converted into polymers or salts. For example, Song et al. [37] applied poly(benzoquinone sulfide) (PBQS) in LIBs and found that the as-fabricated batteries displayed an energy density of $734 \mathrm{~W} \mathrm{~h} \mathrm{~kg}^{-1}$, long-term cycling stability (1000 cycles, $86 \%)$ and superior rate capability (5000 $\left.\mathrm{mA} \mathrm{g}^{-1}, 72 \%\right)$. Wang et al. [38] synthesized 2,5-dihydroxyter-ephthalic acid $\left(\mathrm{Li}_{4} \mathrm{C}_{8} \mathrm{H}_{2} \mathrm{O}_{6}\right)$ and this organiclithium salt presented a superior electrochemical performance with an initial capacity of $223 \mathrm{~mA} \mathrm{~h} \mathrm{~g}^{-1}$ (93\% of $C_{\text {theo }}$ ) and a capacity retention of $95 \%$ after 50 cycles. However, polymerization method could inevitably add dead mass to the active electrode material. In addition, polymerization process could be incomplete and not controllable, and the as-obtained polymers are not easy to be characterized. In addition, the output voltage of organic salts will decrease with the increase of salt groups, which leads to the decrease of energy density of batteries $[37,39]$.

Therefore, to avoid the above-mentioned issues, we synthesized a novel calix[6]quinone (C6Q) oligomer with six $p$-quinones linked by methylene groups at the orthopositions. Compared with $\mathrm{C} 4 \mathrm{Q}, \mathrm{C} 6 \mathrm{Q}$ has the same theoretical specific capacity $\left(C_{\text {theo }}=446 \mathrm{~mA} \mathrm{~h} \mathrm{~g}^{-1}\right)$ but a higher molecular weight $\left(M_{\mathrm{C} 4 \mathrm{Q}}=480, M_{\mathrm{C} 6 \mathrm{Q}}=720\right)$. Moreover, the larger cavity of $\mathrm{C} 6 \mathrm{Q}$ would allow more electrolytes to get in, which would be more favorable for lithiation/delithiation. When C6Q was applied to LIBs at $0.1 \mathrm{C}$, it exhibited a high initial capacity of $423 \mathrm{~mA} \mathrm{~h} \mathrm{~g}^{-1}$, and could maintain 216 and $195 \mathrm{~mA} \mathrm{~h} \mathrm{~g}^{-1}$ after 100 and 300 cycles, respectively. Moreover, utilizing ordered mesoporous carbon (OMC) CMK-3 to immobilize C6Q further improved the electrochemical properties. The capacity increased to $273 \mathrm{~mA} \mathrm{~h} \mathrm{~g}^{-1}$ after 300 cycles. At the same time, the rate performance of $\mathrm{C} 6 \mathrm{Q}$ was also improved.

\section{EXPERIMENTAL SECTION}

\section{Materials preparation}

C6Q was successfully prepared according to the reported synthetic route of C4Q [40]. There were three stepreactions to convert calix[6]arene into C6Q: diazonium coupling, reduction, and oxidation. In the reduction reaction, because the intermediate was easily oxidized, an enhanced method was employed: (1) the reaction was run under inert atmosphere (e.g., $\mathrm{N}_{2}$ ); (2) after the reaction, the product was harvested rapidly through centrifugation to reduce the contact time with air; and (3) oxygen-free water was used to wash the product to further avoid oxidation. The synthetic detail and the characterization of C6Q are provided in Supplementary information (SI). Employing the previous methods to fabricate $\mathrm{C} 4 \mathrm{Q} / \mathrm{CMK}$ 3 composites [14], the C6Q/CMK-3 immobilization mass ratios of $1: 1$ and 1:2 were selected for preparation. Taking C6Q/CMK-3 (1:1) as an example, under $50^{\circ} \mathrm{C}$, the dispersion liquid of $100 \mathrm{mg} \mathrm{CMK}-3$ in $6 \mathrm{~mL} \mathrm{~N}$-methy-1-2pyrrolidone (NMP) was added into the solution of $100 \mathrm{mg}$ C6Q in $8 \mathrm{~mL} \mathrm{NMP,} \mathrm{the} \mathrm{mixture} \mathrm{was} \mathrm{ultra-}$ sonicated for $2 \mathrm{~h}$ at $25^{\circ} \mathrm{C}$, and then dried in vacuum at $90^{\circ} \mathrm{C}$ until the mass no longer reduced.

\section{Materials characterization}

Chemical structure of C6Q was confirmed by Electrospray ionization mass spectrometry (ESI-MS), Infrared spectroscopy (IR), and nuclear magnetic resonance (NMR). ESI-MS was performed with a CQ Finnigan apparatus. IR spectrum was recorded on a FTIR-650 spectrometer. The morphologies of C6Q, C6Q/CMK-3 (1:1) and C6Q/CMK-3 (1:2) were studied on scanning electron microscope (SEM) (JEOL JSM7500F) and transmission electron microscope (TEM) (Philips Tecnai-F20). The crystalline of C6Q/CMK-3 composites were studied through X-ray diffraction (XRD) in the wide $2 \theta$ range of $5^{\circ}-90^{\circ}$ at a speed of $5^{\circ} \mathrm{min}^{-1}$ (D-max-2500/PC, Cu Ka radiation). The characteristic peaks of samples were determined by a standard card comparison. Surface area and pore volume of CMK-3 and C6Q/CMK-3 composites were studied on a Belsorp-Mini instrument by using $\mathrm{N}_{2}$ adsorption-desorption isotherms at $77 \mathrm{~K}$.

\section{Electrochemical investigation}

The cathode slurry was prepared by employing C6Q or C6Q/CMK-3 as the active material, Ketjen Black as the conductive carbon, and polyvinylidene fluoride (PVDF) as the binder (mass ratio: 6:3:1). After sufficiently grinding, the uniform product was coated on $\mathrm{Al}$ foil. After being dried in vacuum oven at $60^{\circ} \mathrm{C}$ for $12 \mathrm{~h}$, the film was cut into circular pieces $(12 \mathrm{~mm}$ in diameter) with the electrode area mass loading of approximately $1.4 \mathrm{mg} \mathrm{cm}^{-2}$. CR2032 coin cells were fabricated in an Ar- 
filled glove box. In the coin cell, the electrolyte was $1 \mathrm{~mol} \mathrm{~L}^{-1} \mathrm{LiPF}_{6}$ in a mixed solvent containing ethylene carbonate (EC) and dimethylcarbonate (DMC) $(1: 1, v / v)$, Celgard 2400 was employed as the separator, and Li tablet was used as the counter electrode. The galvanostatic discharge-charge and rate performance were tested on Land CT2001A. Cyclic voltammogram (CV) and electrochemical impedance spectroscopy (EIS) were conducted on CHI-660E. All the assembly and test processes were carried out at $25^{\circ} \mathrm{C}$.

\section{RESULTS AND DISCUSSION}

ESI-MS (Fig. S1), IR (Fig. S2) and ${ }^{1} \mathrm{H}$ NMR (Fig. S3) confirmed the successful synthesis of C6Q. Fig. S1 shows the charge-to-mass ratio of $\mathrm{C} 6 \mathrm{Q}(\mathrm{m} / z=738.3(\mathrm{M}+$ $\left.\mathrm{NH}_{4}^{+}\right)$), which is consistent with the sum of its molecular weight (720) and $\mathrm{NH}_{4}^{+}$(18). In the infrared spectrum, two absorption peaks at 1655 and $1614 \mathrm{~cm}^{-1}$ are the stretching vibration of the carbonyl group $(\mathrm{C}=\mathrm{O})$, while the peak at $1300 \mathrm{~cm}^{-1}$ belongs to the absorption peak of methylene $\left(-\mathrm{CH}_{2}\right)$. The ${ }^{1} \mathrm{H}$ NMR spectrum of the product is shown in Fig. S3, and the integral ratio of the peaks of $6.63(\mathrm{~s}, 12 \mathrm{H},-\mathrm{CH}=\mathrm{C}-)$ and $3.51\left(\mathrm{~s}, 12 \mathrm{H},-\mathrm{CH}_{2}-\right)$ is $1: 1$, which is in line with the ratio of two hydrogens in the molecule, and the chemical shifts are consistent with the reported result [41].

C6Q, C6Q/CMK-3 (1:1) and C6Q/CMK-3 (1:2) were separately assembled for charging and discharging tests. Fig. 1a is the charge-discharge schematic illustration and Fig. $1 \mathrm{~b}$ is the CV curve of the LIBs with a sweep speed of $0.2 \mathrm{mV} \mathrm{s}^{-1}$. The voltage range is $1.3-3.7 \mathrm{~V}$. There are two reduction peaks $(2.65,2.83 \mathrm{~V}$, where $2.65 \mathrm{~V}$ is a small shoulder peak) and two oxidation peaks $(2.84,3.35 \mathrm{~V})$ respectively, manifesting that the redox process of C6Q is a two-step $\left(12 \mathrm{e}^{-}\right)$electrochemical reaction. In the reduction process, its active sites firstly gained 12 electrons to form anions, and then balanced by $12 \mathrm{Li}^{+}$. Different from the reduction process, the delithiation process in the oxidation reaction is carried out in two steps, corresponding to two oxidation peaks in the CV curve. The shapes and peak areas of the first and second circles in $\mathrm{CV}$ curve are basically the same, indicating that the process is completely reversible.

Fig. 1c shows a comparison of cycle capabilities among C4Q, C6Q and C6Q composites. As we can see, under the condition of $0.1 \mathrm{C}$, the initial discharge capacity of $\mathrm{C} 6 \mathrm{Q}$ reached $95 \%$ of the theoretical capacity $\left(423 \mathrm{~mA} \mathrm{~h} \mathrm{~g}^{-1}\right)$, indicating that all 12 carbonyl groups of $\mathrm{C} 6 \mathrm{Q}$ could participate in the reversible lithiation/delithiation electrode reactions. It is worth noting that the high energy density of $1201 \mathrm{~W} \mathrm{~h} \mathrm{~kg}^{-1}$ exceeds that of conventional inorganic materials. After 100 cycles, the capacity decayed to $216 \mathrm{~mA} \mathrm{~h} \mathrm{~g}^{-1}$ due to the continuous dissolution of $\mathrm{C} 6 \mathrm{Q}$ during the cycle. However, compared with $\mathrm{C} 4 \mathrm{Q}$, the macromolecular structure of $\mathrm{C} 6 \mathrm{Q}$ effectively reduced its dissolution rate, which could be verified by qualitative immersion experiment. Fig. S4 compares the color change of $\mathrm{C} 4 \mathrm{Q}, \mathrm{C} 6 \mathrm{Q}$ and $\mathrm{C} 6 \mathrm{Q}$ composite cathodes soaked in electrolytes after 1,15 , and 30 days, and it can be found that the color change of $\mathrm{C} 4 \mathrm{Q}$ is the most obvious, while $\mathrm{C} 6 \mathrm{Q}$ has a slight change and $\mathrm{C} 6 \mathrm{Q} / \mathrm{CMK}-3$ composites almost have no change. These results suggest that C6Q has a smaller solubility than C4Q, and CMK-3 could further reduce the dissolution rate of $\mathrm{C} 6 \mathrm{Q}$ in traditional electrolytes. It can also be seen from Fig. 1c that the cyclic performance of C6Q was improved after immobilization of C6Q in CMK-3, where C6Q/CMK-3 (1:2) performed outstandingly with a capacity of $273 \mathrm{~mA} \mathrm{~h} \mathrm{~g}^{-1}$ (63\% of capacity retention) after 300 cycles. Their coulumbic efficiency (nearly 100\%) indicates that they have great charge/discharge reversibility (Fig. 1d). Fig. 1e, f and Fig. S5 show that the addition of CMK-3 has no influence on the electrochemical performance of $\mathrm{C} 6 \mathrm{Q}$, and the charge-discharge curve shape of pure C6Q is basically the same as the composites.

The rate performance of C6Q and its composites in LIBs was compared and provided in Fig. 1g. A continuous series of charging and discharging tests were performed at different rates of 0.1-1 C. From Fig. S6, we can see that the charge-discharge curves of $\mathrm{C} 6 \mathrm{Q}$ and its composites under different current densities were basically the same. At a low rate of $0.1 \mathrm{C}$, their discharge specific capacities were the same. With the increase of current density, there were no obvious changes in charge-discharge curves. The discharging specific capacities of the composites were significantly higher than that of $\mathrm{C} 6 \mathrm{Q}$. When the current density was $1 \mathrm{C}$, the capacity of C6Q/CMK-3 (1:2) was the highest one; however, there was no significant difference between C6Q and C6Q/CMK-3 (1:1). The possible reason is that, under large current density, the existence of pore structure might slow down the migration process of lithium ions, thereby affecting the electrochemical reaction rate $[42,43]$. When the current rate recovered to $0.1 \mathrm{C}$, the composites showed much higher stable capacity than C6Q, and C6Q/CMK-3 (1:2) showed better performance. It is confirmed that C6Q/CMK-3 composite could enhance the conductivity and rate performance for LIBs.

The surface morphologies of $\mathrm{C} 6 \mathrm{Q}$ and $\mathrm{C} 6 \mathrm{Q} / \mathrm{CMK}-3$ composites were studied by SEM (Fig. 2a-d). Fig. 2a re- 
a

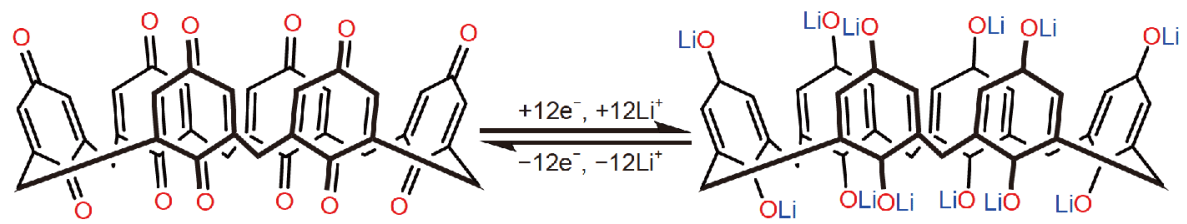

$\mathrm{C}_{42} \mathrm{H}_{24} \mathrm{O}_{12}$
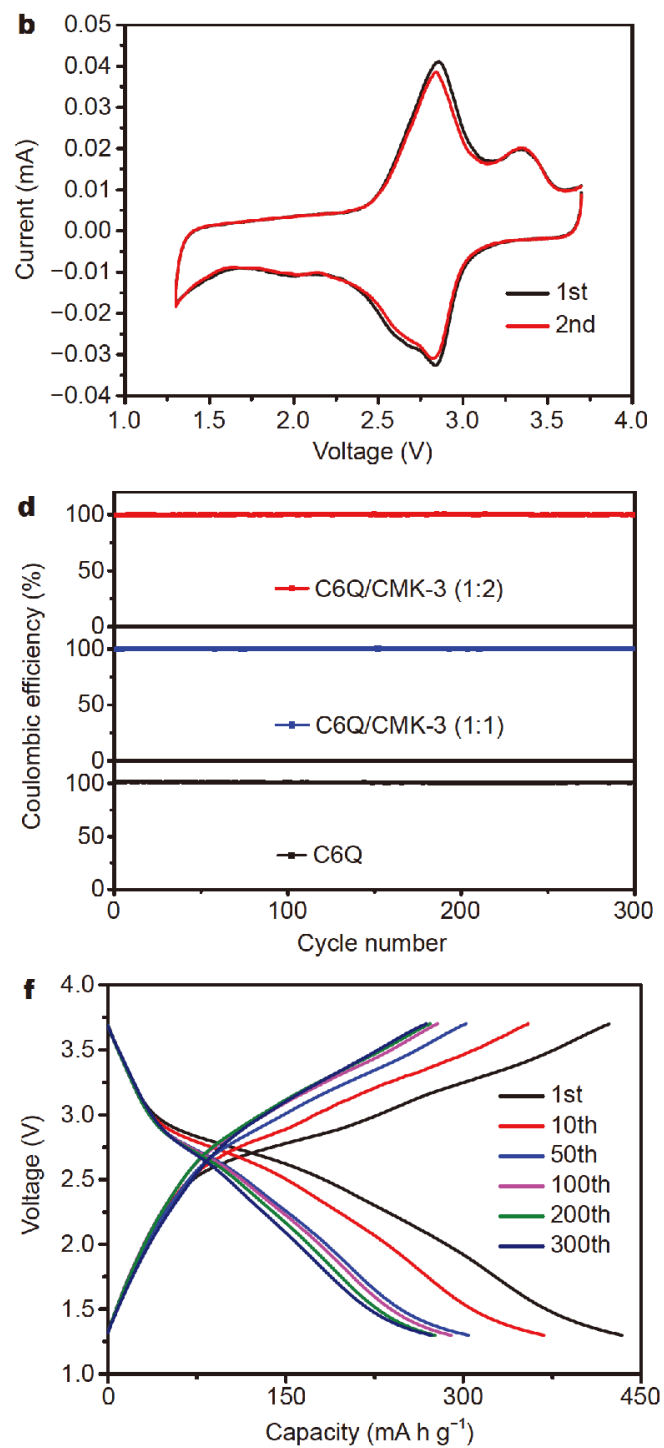

$\mathrm{Li}_{12} \mathrm{C}_{42} \mathrm{H}_{24} \mathrm{O}_{12}$
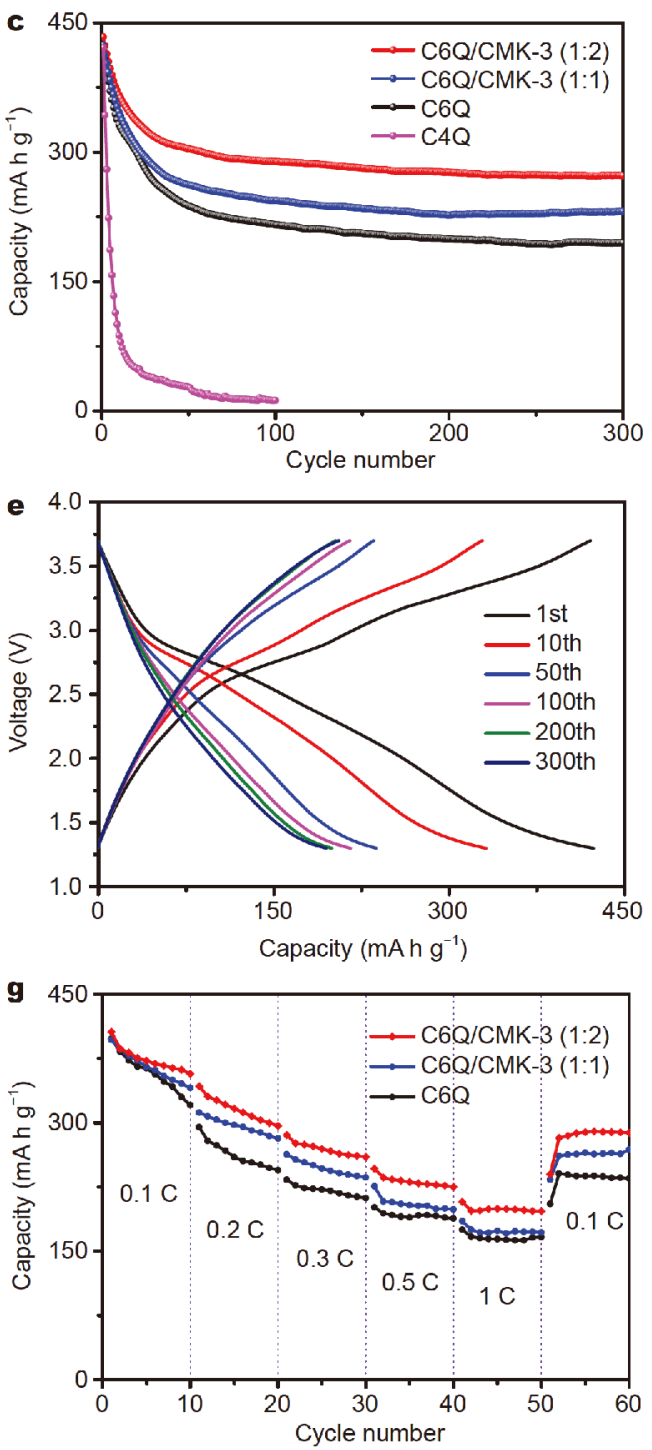

Figure 1 (a) The proposed electrochemical redox of C6Q. (b) CV of C6Q at $0.2 \mathrm{mV} \mathrm{s}^{-1}$. (c) Cyclic properties of C6Q/CMK-3 composites, C6Q and C4Q. (d) Coulombic efficiency of C6Q and C6Q/CMK-3 composites. (e) The charge-discharge curves of C6Q. (f) The charge-discharge curves of C6Q/CMK-3 (1:2). (g) Rate capability of C6Q and C6Q/CMK-3 composites.

veals that $\mathrm{C} 6 \mathrm{Q}$ possesses olive-shaped microstructures and CMK-3 has a large specific surface area and pore volume. The pore structure and the smooth surface of CMK-3 can be seen clearly in Fig. 2b. Fig. 2 c, d do not show any obvious crystal particles on the surface of CMK-3. Correspondingly, there is no characteristic dif- fraction peak of C6Q appearing in XRD pattern (Fig. 3). The TEM and TEM-mapping performed separately for C6Q/CMK-3 (1:2) suggest that C6Q is evenly distributed in CMK-3 (Fig. 2e-h). Fig. S7 shows that after 300 cycles of charge-discharge experiment, the morphology of composite materials is almost unchanged, indicating that 


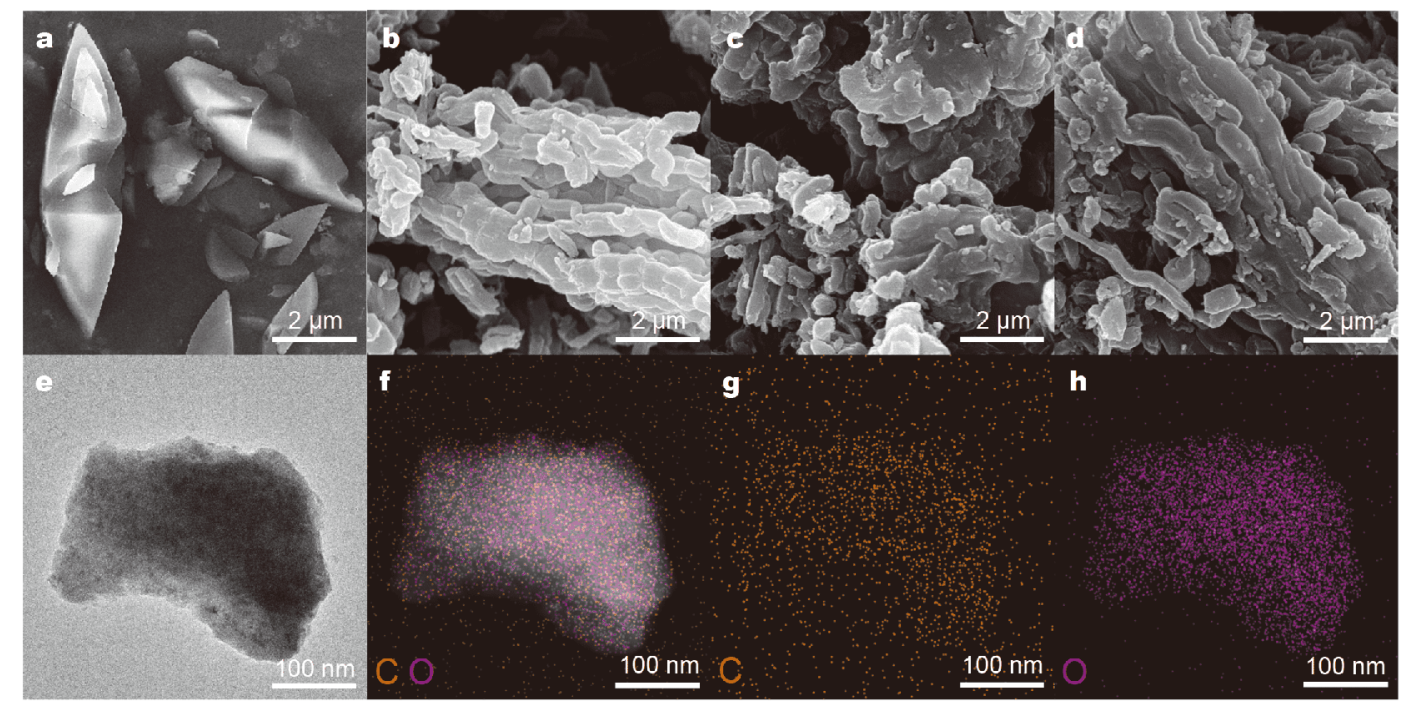

Figure 2 SEM images of CMK-3 and C6Q/CMK-3 composites (a) C6Q, (b) CMK-3, (c) C6Q/CMK-3 (1:1), and (d) C6Q/CMK-3 (1:2). (e) TEM image of C6Q/CMK-3 (1:2). (f-h) TEM-mapping of C6Q/CMK-3 (1:2).

their structure is relatively stable.

The XRD patterns of C6Q and its composites are revealed in Fig. 3. C6Q has a relatively strong diffraction peak, corresponding to its great crystal structure. The peaks at $26^{\circ}$ and $44^{\circ}$ in the XRD pattern of CMK-3 are in line with the (002) and (100) crystal plane respectively, suggesting its graphitization structure. C6Q composites have the same peak shape as CMK-3 beyond $17^{\circ}$. This finding is consistent with the results of previous studies on C4Q/CMK-3 [43].

$\mathrm{N}_{2}$ adsorption and desorption tests of CMK-3 and C6Q composites were conducted, and their testing results are shown in Fig. 4. According to Fig. 4a, CMK-3 has a large pore volume and can adsorb a large amount of $\mathrm{N}_{2}$. After the encapsulation of $\mathrm{C} 6 \mathrm{Q}$ into the pore of CMK-3, the pore volume becomes smaller and smaller. Especially, when the ratio of $\mathrm{C} 6 \mathrm{Q}$ was $50 \%$, the adsorption amount of $\mathrm{N}_{2}$ reached the minimum. Fig. $4 \mathrm{~b}$ evinces that the specific surface area of CMK-3 reaches $1073.4 \mathrm{~m}^{2} \mathrm{~g}^{-1}$, the pore volume is $1.28 \mathrm{~cm}^{3} \mathrm{~g}^{-1}$, and the pore diameter distribution is around $3.8 \mathrm{~nm}$. These results suggest that CMK-3 is an ordered mesoporous material with a large specific surface area and pore volume. As the ratio of C6Q continued increasing, the specific surface area and pore volume of $\mathrm{C} 6 \mathrm{Q}$ decreased rapidly. The specific surface area of C6Q/CMK-3 (1:2) dropped to $270.47 \mathrm{~m}^{2} \mathrm{~g}^{-1}$, and the pore volume changed into $0.25 \mathrm{~cm}^{3} \mathrm{~g}^{-1}$. By further increasing the content of C6Q, the specific surface area of C6Q/CMK-3 (1:1) reached $110.87 \mathrm{~m}^{2} \mathrm{~g}^{-1}$, and the pore volume was reduced to

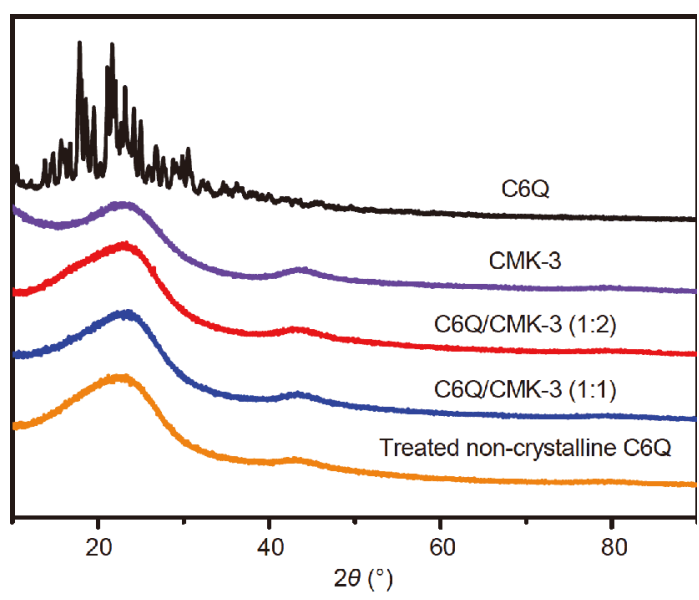

Figure 3 XRD patterns of C6Q and C6Q/CMK-3 composites.

$0.13 \mathrm{~cm}^{3} \mathrm{~g}^{-1}$. This result suggests that C6Q has been filled completely into the pore of CMK-3 at the ratio of 1:1.

C6Q/CMK-3 (1:2) composites have the best performance by studying the cyclic performance of $\mathrm{C} 6 \mathrm{Q}$ and C6Q composites in LIBs. The EIS of C6Q and C6Q/ CMK-3 (1:2) were compared, and the kinetic processes in the electrochemical reaction between them were studied. The voltage of each cell during EIS was around $3.50 \mathrm{~V}$. The impedance changes of these two materials were measured after different cycles, and the results are shown in Fig. 5. The EIS of C6Q and C6Q/CMK-3 (1:2) are made up of semicircle (high frequency region) and diagonal (low frequency region). The diameter of the 

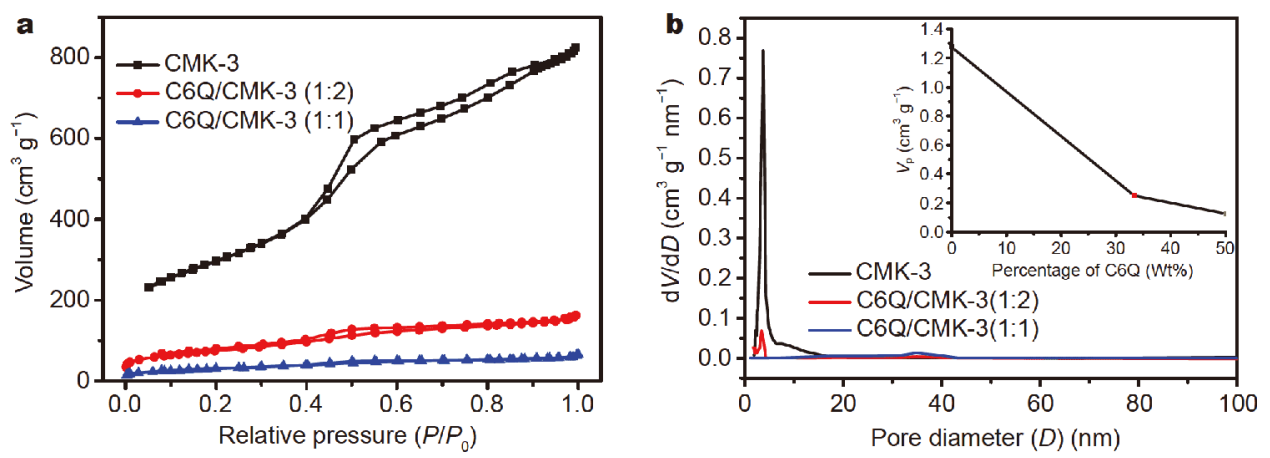

Figure 4 (a) $\mathrm{N}_{2}$ adsorption and desorption curves of CMK-3 and C6Q/CMK-3 composites. (b) Pore distribution curves and pore volume curves for CMK-3 and C6Q/CMK-3 composites.
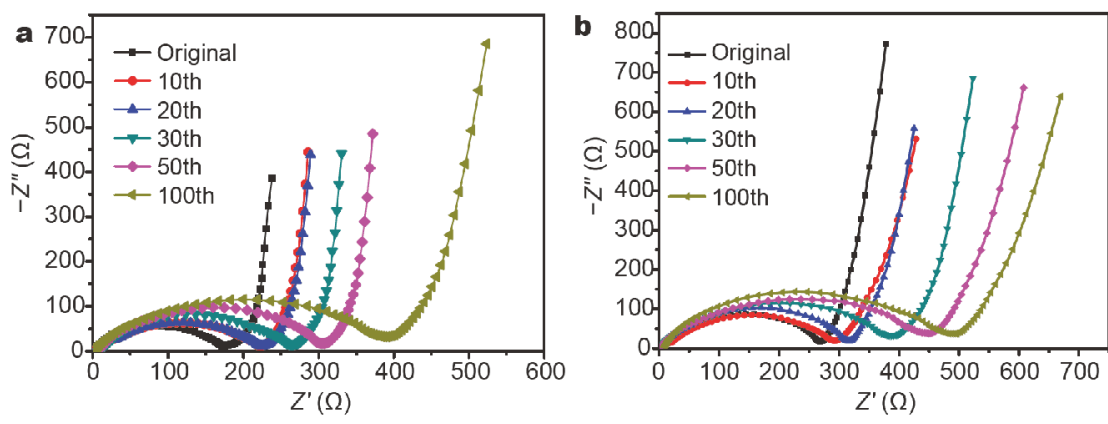

c

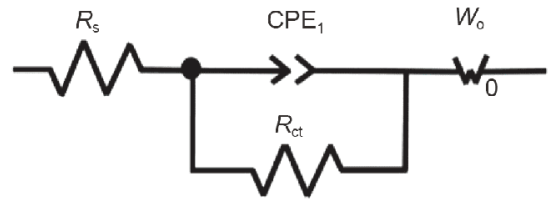

Figure 5 The EIS during the cycle of LIBs (a) C6Q/CMK-3 (1:2), (b) C6Q. (c) The corresponding equivalent circuit.

semicircle in the high frequency region is positively correlated with the magnitude of the charge transfer resistance. The initial impedances of C6Q/CMK-3 (1:2) were significantly lower than that of C6Q. With the increase of cycle numbers, their charge-transfer impedance values rose gradually. However, the impedance values of C6Q/CMK-3 (1:2) were still lower than those of C6Q due to its lower rate of dissolution in traditional organic electrolytes.

\section{CONCLUSIONS}

In summary, we have successfully synthesized C6Q and applied it as cathode materials in LIBs with an initial capacity up to $423 \mathrm{~mA} \mathrm{~h} \mathrm{~g}^{-1}$ (about $95 \%$ of theoretical capacity). The electrochemical performances of $\mathrm{C} 4 \mathrm{Q}$ and C6Q have been compared. C6Q with a large cyclic structure possesses a more stable cycling performance, a more excellent rate performance and a less impedance compared with $\mathrm{C} 4 \mathrm{Q}$. After 300 cycles, the capacity of C6Q still maintained $195 \mathrm{~mA} \mathrm{~h} \mathrm{~g}^{-1}$. In addition, the encapsulation of $\mathrm{C} 6 \mathrm{Q}$ into CMK-3 not only further enhances the cycling performance of $\mathrm{C} 6 \mathrm{Q}$ but also achieves better rate capability. Our results suggest that larger cyclic structure in $\mathrm{C} x \mathrm{Q}$ family should be excellent candidates as cathode materials in LIBs.

Received 24 August 2019; accepted 12 September 2019; published online 23 October 2019

1 Tarascon JM, Armand M. Issues and challenges facing rechargeable lithium batteries. Nature, 2001, 414: 359-367

2 Armand M, Tarascon JM. Building better batteries. Nature, 2008, 451: $652-657$

3 Häupler B, Wild A, Schubert US. Carbonyls: powerful organic materials for secondary batteries. Adv Energy Mater, 2015, 5: 1402034

4 Kim H, Kwon JE, Lee B, et al. High energy organic cathode for sodium rechargeable batteries. Chem Mater, 2015, 27: 7258-7264

5 An $\mathrm{D}$, Shen $\mathrm{L}$, Lei $\mathrm{D}$, et al. An ultrathin and continuous $\mathrm{Li}_{4} \mathrm{Ti}_{5} \mathrm{O}_{12}$ coated carbon nanofiber interlayer for high rate lithium sulfur battery. J Energy Chem, 2019, 31: 19-26

6 Shi K, Lai C, Liu X, et al. $\mathrm{LiNi}_{0.8} \mathrm{Co}_{0.15} \mathrm{Al}_{0.05} \mathrm{O}_{2}$ as both a trapper and accelerator of polysulfides for lithium-sulfur batteries. Energy Storage Mater, 2019, 17: 111-117

7 Xie J, Zhang Q. Recent progress in rechargeable lithium batteries with organic materials as promising electrodes. J Mater Chem A, 2016, 4: 7091-7106

8 Xie J, Gu P, Zhang Q. Nanostructured conjugated polymers: toward high-performance organic electrodes for rechargeable batteries. ACS Energy Lett, 2017, 2: 1985-1996 
$9 \mathrm{Wu} \mathrm{Z}$, Xie J, Xu ZJ, et al. Recent progress in metal-organic polymers as promising electrodes for lithium/sodium rechargeable batteries. J Mater Chem A, 2019, 7: 4259-4290

10 Xu G, Pang C, Chen B, et al. Prescribing functional additives for treating the poor performances of high-voltage (5 V-class) $\mathrm{LiNi}_{0.5} \mathrm{Mn}_{1.5} \mathrm{O}_{4} / \mathrm{MCMB}$ Li-ion batteries. Adv Energy Mater, 2018, 8: 1701398

11 Lu Y, Zhao Q, Miao L, et al. Flexible and free-standing organic/ carbon nanotubes hybrid films as cathode for rechargeable lithium-ion batteries. J Phys Chem C, 2017, 121: 14498-14506

12 Zhu Z, Chen J. Review-Advanced carbon-supported organic electrode materials for lithium (sodium)-ion batteries. J Electrochem Soc, 2015, 162: A2393-A2405

13 Wang S, Sun C, Wang N, et al. Ni- and/or Mn-based layered transition metal oxides as cathode materials for sodium ion batteries: status, challenges and countermeasures. J Mater Chem A, 2019, 7: 10138-10158

14 Li C, Han X, Cheng F, et al. Phase and composition controllable synthesis of cobalt manganese spinel nanoparticles towards efficient oxygen electrocatalysis. Nat Commun, 2015, 6: 7345

15 Liang Y, Tao Z, Chen J. Organic electrode materials for rechargeable lithium batteries. Adv Energy Mater, 2012, 2: 742-769

16 Zhang $\mathrm{Z}$, Liao $\mathrm{M}$, Lou $\mathrm{H}$, et al. Conjugated polymers for flexible energy harvesting and storage. Adv Mater, 2018, 30: 1704261

17 Ni Q, Bai Y, Wu F, et al. Polyanion-type electrode materials for sodium-ion batteries. Adv Sci, 2017, 4: 1600275

18 Zhang Y, Wang J, Riduan SN. Strategies toward improving the performance of organic electrodes in rechargeable lithium (sodium) batteries. J Mater Chem A, 2016, 4: 14902-14914

19 Yao CJ, Xie J, Wu Z, et al. A conjugated copolymer of $N$-phenyl-pphenylenediamine and pyrene as promising cathode for rechargeable lithium-ion batteries. Chem Asian J, 2019, 14: 2210-2214

20 Xie J, Zhang Q. Recent progress in multivalent metal (Mg, Zn, Ca, and $\mathrm{Al}$ ) and metal-ion rechargeable batteries with organic materials as promising electrodes. Small, 2019, 15: 1805061

21 Zhan X, Chen Z, Zhang Q. Recent progress in two-dimensional COFs for energy-related applications. J Mater Chem A, 2017, 5: 14463-14479

22 Xie J, Zhao CE, Lin ZQ, et al. Nanostructured conjugated polymers for energy-related applications beyond solar cells. Chem Asian J, 2016, 11: 1489-1511

$23 \mathrm{Gu} \mathrm{S}, \mathrm{Wu} \mathrm{S}$, Cao L, et al. Tunable redox chemistry and stability of radical intermediates in $2 \mathrm{D}$ covalent organic frameworks for high performance sodium ion batteries. J Am Chem Soc, 2019, 141: 9623-9628

24 Muench S, Wild A, Friebe C, et al. Polymer-based organic batteries. Chem Rev, 2016, 116: 9438-9484

25 Song Z, Zhou H. Towards sustainable and versatile energy storage devices: an overview of organic electrode materials. Energy Environ Sci, 2013, 6: 2280-2301

26 Wild A, Strumpf M, Häupler B, et al. All-organic battery composed of thianthrene- and TCAQ-based polymers. Adv Energy Mater, 2016, 7: 1601415

27 Zhao Q, Zhu Z, Chen J. Molecular engineering with organic carbonyl electrode materials for advanced stationary and redox flow rechargeable batteries. Adv Mater, 2017, 29: 1607007

28 Zhang K, Guo C, Zhao Q, et al. High-performance organic lithium batteries with an ether-based electrolyte and 9,10-anthraquinone (AQ)/CMK-3 cathode. Adv Sci, 2015, 2: 1500018

29 Huang W, Zhu Z, Wang L, et al. Quasi-solid-state rechargeable lithium-ion batteries with a calix[4]quinone cathode and gel polymer electrolyte. Angew Chem Int Ed, 2013, 52: 9162-9166

30 Zheng $\mathrm{S}, \mathrm{Hu}$ J, Huang W. An inorganic-organic nanocomposite calix[4]quinone (C4Q)/CMK-3 as a cathode material for high-capacity sodium batteries. Inorg Chem Front, 2017, 4: 1806-1812

31 Yan B, Wang L, Huang W, et al. High-capacity organic sodium ion batteries using a sustainable C4Q/CMK-3/SWCNT electrode. Inorg Chem Front, 2019, 6: 1977-1985

32 Zheng S, Sun H, Yan B, et al. High-capacity organic electrode material calix[4]quinone/CMK-3 nanocomposite for lithium batteries. Sci China Mater, 2018, 61: 1285-1290

33 Zhu Z, Hong M, Guo D, et al. All-solid-state lithium organic battery with composite polymer electrolyte and pillar[5]quinone cathode. J Am Chem Soc, 2014, 136: 16461-16464

34 Xiong $\mathrm{W}$, Huang $\mathrm{W}$, Zhang $\mathrm{M}$, et al. Pillar[5]quinone-carbon nanocomposites as high-capacity cathodes for sodium-ion batteries. Chem Mater, 2019, acs.chemmater.9b02601

35 Song Z, Qian Y, Gordin ML, et al. Polyanthraquinone as a reliable organic electrode for stable and fast lithium storage. Angew Chem Int Ed, 2015, 54: 13947-13951

36 Kim H, Seo DH, Yoon G, et al. The reaction mechanism and capacity degradation model in lithium insertion organic cathodes, $\mathrm{Li}_{2} \mathrm{C}_{6} \mathrm{O}_{6}$, using combined experimental and first principle studies. J Phys Chem Lett, 2014, 5: 3086-3092

37 Song Z, Qian Y, Zhang T, et al. Poly(benzoquinonyl sulfide) as a high-energy organic cathode for rechargeable $\mathrm{Li}$ and $\mathrm{Na}$ batteries. Adv Sci, 2015, 2: 1500124

38 Wang $\mathrm{S}$, Wang L, Zhang $\mathrm{K}$, et al. Organic $\mathrm{Li}_{4} \mathrm{C}_{8} \mathrm{H}_{2} \mathrm{O}_{6}$ nanosheets for lithium-ion batteries. Nano Lett, 2013, 13: 4404-4409

39 Abouimrane A, Weng W, Eltayeb $\mathrm{H}$, et al. Sodium insertion in carboxylate based materials and their application in $3.6 \mathrm{~V}$ full sodium cells. Energy Environ Sci, 2012, 5: 9632

40 Morita Y, Agawa T, Nomura E, et al. Syntheses and NMR behavior of calix[4]quinone and calix[4]hydroquinone. J Org Chem, 1992, 57: $3658-3662$

41 Reddy PA, Kashyap RP, Watson WH, et al. Calixarenes 30. Calixquinones. Isr J Chem, 1992, 32: 89-96

42 Wang $\mathrm{Y}$, Ding $\mathrm{Y}$, Pan L, et al. Understanding the size-dependent sodium storage properties of $\mathrm{Na}_{2} \mathrm{C}_{6} \mathrm{O}_{6}$-based organic electrodes for sodium-ion batteries. Nano Lett, 2016, 16: 3329-3334

43 Zhu Z, Wang S, Du J, et al. Ultrasmall Sn nanoparticles embedded in nitrogen-doped porous carbon as high-performance anode for lithium-ion batteries. Nano Lett, 2014, 14: 153-157

Acknowledgements The authors acknowledge the financial support of the National Natural Science Foundation of China (21875206 and 21403187), China Postdoctoral Science Foundation (2015T80229) and the Natural Science Foundation of Hebei Province (B2019203487).

Author contributions Huang W and Zhang X wrote the paper. Zhang $\mathrm{X}$ conducted a series of electrochemical tests. Zheng $\mathrm{S}$ prepared the $\mathrm{C} 6 \mathrm{Q}$ and performed tests such as TEM, IR, and NMR. Zhou W collected the data and analyzed the results. Xie J modified the article. Huang W, Yang $\mathrm{Z}$ and Zhang Q supervised the project and conceived the experiments. All authors contributed to the general discussion.

Conflict of interest There are no conflicts to declare.

Supplementary information Experimental details and supporting data are available in the online version of the paper. 


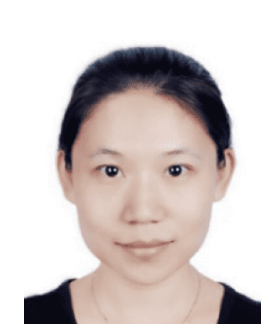

Weiwei Huang obtained her BSc degree at Hebei Normal University of Science \& Technology in 2005, MSc degree of inorganic chemistry at Hebei Normal University in 2008 and $\mathrm{PhD}$ degree of physical chemistry at Nankai University in 2011. Then, she joined Prof. Jun Chen's group at Nankai University as a postdoctoral fellow. In 2013, she joined the School of Environmental and Chemical Engineering at Yanshan University as an associate professor. She is currently studying at Nanyang Technological University as a visiting scholar. Her research is focused on the organic electrode materials for $\mathrm{Li} / \mathrm{Na}$ batteries.

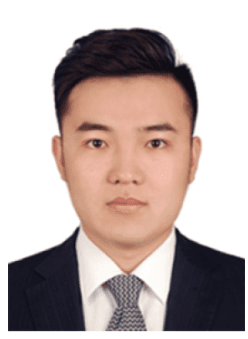

Xueqian Zhang obtained his BSc degree of materials science and engineering at Yanshan University in 2017. He is currently a Master candidate under the joint guidance of Prof. Weiwei Huang and Prof. Zhinan Yang at Yanshan University. His research mainly focuses on the synthesis and preparation of organic electrode materials in $\mathrm{Li} / \mathrm{Na}$ batteries and investigation of electrolytes.

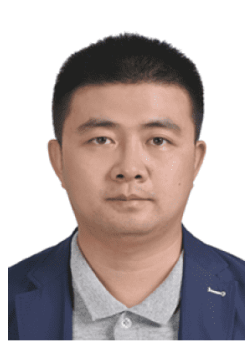

Zhinan Yang obtained his BSc degree at Xi'an University of Science and Technology in 2008, and $\mathrm{PhD}$ degree in engineering at Yanshan University in 2013. Then, he joined the School of Mechanical Engineering of Yanshan University as a lecturer, and has been an associate professor since 2017. He worked as a visiting scholar at the University of New South Wales in Australia and the University of Cambridge in the UK. His research is focused on the advanced structural materials preparation techniques.

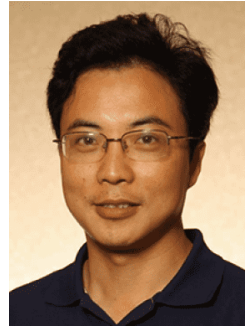

Qichun Zhang is an Associate Professor at the School of Materials Science and Engineering, Nanyang Technological University, Singapore. His research focuses on conjugated rich carbon materials and applications. Currently, he is an associate editor for J. Solid State Chemistry, Advisory board members of Materials Chemistry Frontiers, Chemistry-an Asian Journal, Journal of Materials Chemistry C, and Inorganic Chemistry Frontiers. He is also a fellow of the Royal Society of Chemistry. In 2018 and 2019, he has been recognized as one of highly-cited researchers (top 1\%) in cross-field in Clarivate Analytics. Till now, he has published more than 327 papers (H-index: 67) and filed 4 patents.

\section{高性能锂离子电池正极Calix[6]quinone}

黄苇苇 ${ }^{1,3 \dagger^{*}}$, 掌学谦 ${ }^{2 \dagger}$, 郑仕兵 ${ }^{1}$, 周文君 ${ }^{1}$, 谢健 ${ }^{3}$, 杨志南 ${ }^{2 *}$, 张其春 $^{3}$

摘要 有机醌类化合物因其具有高的理论容量值而引起了人们的广 泛关注. 本文合成了一种新型的环状大分子Calix[6]quinone (C6Q), 它由 6 个对苯醌单元组成, 可提供 12 个电化学位点, 是一种极具发展 前景的锂离子正极材料. $\mathrm{C} 6 \mathrm{Q}$ 在 $0.1 \mathrm{C}$ 的电流密度下展示了高达 $423 \mathrm{~mA} \mathrm{~h} \mathrm{~g}^{-1}$ 的初始放电比容量(理论放电比容量为 $447 \mathrm{~mA} \mathrm{~h} \mathrm{~g}^{-1}$ ). 经过 100 圈充放电循环之后, 它的容量保持在 $216 \mathrm{~mA} \mathrm{~h} \mathrm{~g}^{-1}$; 经过 300 次循环之后, 仍然拥有 $195 \mathrm{~mA} \mathrm{~h} \mathrm{~g}^{-1}$ 的高容量. C6Q具有高容量和宽 的电化学窗口, 因此可以提供高达 $1201 \mathrm{~W} \mathrm{~h} \mathrm{~kg}^{-1}$ 的能量密度. 此外, 使用有序介孔碳CMK-3固载C6Q的方法可以进一步提高 $\mathrm{C} 6 \mathrm{Q}$ 的电化 学性能. 